\title{
CONTORNOS DE LA SEMBLANZA DE UN ACTOR CORTESANO: JUAN RANA*
}

\author{
Julio Vélez Sainz \\ (ITEM \& Universidad Complutense de Madrid) \\ jivelez@ucm.es
}

\section{RESUMEN}

Carecemos de documentos iconográficos que representen de manera fiable a Cosme Pérez, posiblemente el actor más famoso del Siglo de Oro. De hecho, hay un disenso crítico sobre su forma física y sobre si esta tenía repercusión en su manera de actuar, en su percepción por parte del gran público y de los autores. En el presente trabajo, trazo una recopilación y análisis de sus retratos de modo que se presentan las semblanzas más cercanas a su persona. Analizo iconográficamente la representación más conocida: el retrato de Real Academia Española así como el uso escénico de esta imagen en la producción de Ron Lalá/Compañía Nacional de Teatro Clásico, Andanz̧as y entremeses de Juan Rana (2019). Después, desarrollo la historia y recepción de Retrato de Felipe IV con lacayo o Felipe IV junto a dos servidores de Gaspar de Crayer, que tiene una segura conexión con el personaje retratado en la lámina de la Real Academia Española. También señalo su presencia en el manuscrito de La fábula de Perseo y Andrómeda de Calderón que se conserva en la Houghton Library de la Universidad de Harvard (Ms Typ 258) tal y como la crítica ha destacado (Dearborn Massar, Sáez Raposo, Lobato, de Miguel). Finalmente, mantengo cómo no podemos tener tampoco certeza de la atribución de este personaje a Juan Rana. Para ello, me baso en pruebas caligráficas. Concluyo que, lamentablemente, no hay una semblanza exacta del actor.

PALABRAS CLAVE: Juan Rana, Actor, Retratos, Gaspar Crayer, Calderón de la Barca

* El siguiente trabajo se inserta dentro de los objetivos investigadores del Instituto del Teatro de Madrid de la UCM, el Seminario de Estudios Teatrales (930128, UCM) y del proyecto CARTEMAD: Cartografía digital, conservación y difusión del patrimonio teatral del Madrid contemporáneo (H2019/HUM-5722) de la convocatoria de ayudas para la realización de programas de actividades de $\mathrm{I}+\mathrm{D}$ entre grupos de investigación de la Comunidad de Madrid en Ciencias Sociales y Humanidades (2019). 


\title{
FRAMING THE SEMBLANCE OF A COURTLY ACTOR: JUAN RANA
}

\begin{abstract}
There is a lack of iconographic documents that reliably represent Cosme Pérez, possibly the most famous Golden Age actor. This triggers a critical dissent about his physical form and whether his demeanor had an impact on his acting, the general public and on his perception. In this paper, I collect a number of his supposed portraits. First, I analyze iconographically his best-known portrait: that housed in Real Academia Española as well as the scenic use of this image in Ron Lalá's production, Andanzas y entremeses de Juan Rana (2019). Then, I describe the reception of Gaspar de Crayer's Retrato de Felipe IV con lacayo o Felipe IV junto a dos servidores, which surely represents the same character portrayed in the Real Academia Española, whoever this might be. I also point to his presence in the famous Harvard Houghton Library's manuscript of Calderón's La fábula de Perseo y Andrómeda, which critics such as Dearborn Massar, Sáez Raposo, Lobato, de Miguel have shown to be a probable representation of the actor. Finally, I caligraphically analyze this manuscript and confirm that there is no certainty for this specific attribution either.
\end{abstract}

KEYWORDS: Juan Rana, Actor, Portraits, Gaspar Crayer, Calderón de la Barca

Cosme Pérez (Tudela de Duero, Valladolid, principios de abril de 1593-Madrid, 20 de abril de 1672) es posiblemente el actor más famoso que ha dado el Siglo de Oro. Estuvo en la compañía de Juan Bautista Valenciano y de Hernán Sánchez de Vargas de 1617 a 1622, en la de Antonio de Prado en 1624, en la de Tomás Fernández de 1631 a 1635 y, posteriormente, en la de Pedro de la Rosa entre 1636 y 1644 (Madroñal Durán 2012, 68). Hacia 1650 recaló en la compañía de Antonio de Prado, donde formaría una memorable pareja cómica con Bernarda Ramírez. Falleció en Madrid el 20 de abril de 1672, a los 79 años.

Francisco Sáez Raposo (2005) contabiliza más de 80 obras entre comedias, entremeses, jácaras, mojigangas en las que Cosme Pérez aparece, bien representando su máscara favorita («Juan Rana»), bien representando otros papeles. Especialista en entremeses, cuenta con más de cuarenta escritos para su personaje de Juan Rana. Sus recursos cómicos eran amplios y prácticamente todos los autores teatrales de importancia del Siglo de Oro lo incluyeron en sus elencos, pues solo con salir a las tablas y sin hablar provocaba risa y aplauso. En la Loa a los años de su alteza, de Francisco de Avellaneda, que se publicó en Verdores del Parnaso (Madrid, 1668), y en La portería de las damas hace de un desmemoriado. En El doctor Juan Rana, de Luis Quiñones de 
Benavente, hace de un médico ridículo cercano al dottore de la commedia dell'arte. Hace de poeta en Juan Rana poeta, de Antonio de Solís, y de mujer en Juan Rana mujer, de Jerónimo de Cáncer. Otras veces representa un retrato o una estatua de sí mismo, como en El retrato vivo, de Agustín de Moreto y Cañada, de torero en Juan Rana toreador, de Calderón, de novio en La boda de Juan Rana o de parturienta en Elparto de Juan Rana, de Lanini y Sagredo. La primera edición conocida de La boda de Juan Rana (Rasgos del ocio, 1664) está atribuida a Avellaneda; en 1691 se volvió a imprimir en Floresta de entremeses, esta vez a nombre de Jerónimo de Cáncer (¿1582?-1655); este parece ser el criterio seguido por Cotarelo para adjudicar el entremés al primero (1998, lxxxvi). Actuó en los entremeses El toreador, El desafio de Juan Rana, la mojiganga de Los sitios de recreación del rey, el entremés Los dos Juan Rana, todos de Pedro Calderón. Incluso era práctica común anunciar su intervención en una comedia para atraer a los espectadores.

Abraham Madroñal afirma que su entrada en las tablas tuvo lugar en 1616 con la obra lopesca Quien más no puede, en el papel de Nuño (2012, 18-21). En 1617 participaría como «Cosme» en El desdén vengado, de Lope de Vega, puesta en escena en ese mismo año y en 1622. También en La nueva victoria de don Gonzalo Fernández de Córdoba, de Lope, estrenada en octubre de 1622, y en La infelice Dorotea, de Claramonte, con representaciones en 1621 y 1622 (DICAT). Por lo menos desde 1631 ya se le conoce con el nombre de Juan Rana. En ese año ingresó en la Cofradía de la Novena junto a su mujer María Acosta y su hija Francisca María Pérez, cuando todos trabajaban en la compañía de Tomás Fernández Cabredo. Vivió gran parte de su vida en la calle Cantarranas, hoy Lope de Vega, de Madrid (Sáez Raposo 2004, 333) y murió tras escribir dos testamentos encontrados por Agustín de la Granja (2001). Entre 1634 y 1635 tiene una profusa actividad entremesil y se anota su participación en los entremeses El guardainfante (en dos partes), El soldado y El doctor Juan Rana, de Quiñones de Benavente, representados por Tomás Fernández los dos primeros y por Pedro de la Rosa el último.

En la Academia burlesca celebrada en el Buen Retiro en 1637 se introducen «doce redondillas [que] digan la razón por que las beatas no tienen unto, y si basta la opinión del doctor Juan Rana para que se crea» (Ferrer Valls, DICAT, Cotarelo CLVIII). Es decir, sin duda actuaba ya para el monarca en el 37, órbita en la que no dejaría de trabajar. En una carta de fecha 18 de octubre de 1649, Felipe IV declara ante la condesa de Paredes de Nava, doña Luisa Enríquez Manrique de Lara: «tenemos por guesped a Juan Rana que siempre está de tan buen umor como le dejastes» (Lobato 1999, 80), en lo que insiste en misiva fechada el 9 de junio de 1648, cuando dice ante la condesa, quien había ingresado en el convento de San José de Malagón: «Os echo mucho de menos para los autos, que me dicen que vuestro amigo Juan Rana hace famoso papel, y se me acuerda de lo que os hacía reír» (Lobato 1999, 82). La amistad entre doña Luisa y el actor se remontaba a años atrás. También le tuvo favor Carlos II, aunque en esa época sólo actuaba por excepción, pues era ya muy viejo, y en 1665 hizo uno de sus últimos papeles con ochenta años en las fiestas de Pascua. Muy posiblemente pudiéramos datar ya una temprana relación entre Felipe IV y los actores de la compañía de Tomás Fernández. De 1635 tenemos un documento en el que aparece como testigo 
este, quien firma como «autor de comedias por su majestad» (Davis y Varey 2003 II, 19-20).

Los datos biográficos que poseemos del tudelano inciden en que, más que probablemente, obtuvo a lo largo de su vida los favores reales destinados a los protegidos por el rey. Uno de los más sonados fue la «intercesión real» en favor de la comedianta, sobrina de Juan Rana, Bárbara Coronel, encarcelada bajo la acusación de asesinar a su propio marido. La Genealogía recoge noticia de la comediante, que «mató [a Francisco Jalón] con aiuda de un mozo apuntador con quien ella tenía correspondencia. Diéronla sentencia de muerte y estando para executarla en Guadalaxara pidió por ella [al] Rey Juan Rana y se libró del suplicio» $(1985,422)$. Su influencia no hubo de ser menor en algunos momentos de su vida. Recordemos que Cosme Pérez quedó viudo en 1635 y un año después los rumores sobre su homosexualidad se tradujeron en una acusación formal. En 1636 lo acusan formalmente de pecado nefando, algo con que los dramaturgos jugaron (Thompson 2006) y que podía deberse a su atiplada voz. De todos los acusados fue el único que no llegó al cadalso. Atribuyen a su extrema popularidad que la Inquisición no se atreviera a encausarlo. Indica Serralta: «en cuanto al negocio de los que están presos por el pecado nefando, no se usa del rigor que se esperaba, o sea esto porque el ruido ha sido mayor que las nueces, o sea que verdaderamente el poder y el dinero alcanzan lo que quieren. A don Nicolás, el paje del conde de Castrillo, vemos que anda por la calle, y a Juan Rana, famoso representante, han soltado» (1990, 82). Confirma Sáez Raposo que estuvo envuelto en un proceso inquisitorial por prácticas sodomíticas y que se libró por la «intercesión anónima de una personalidad poderosa» (2004, 43). Es decir, fuera o no homosexual, en la corte tenía una gran influencia. En modo barrococortesano, podemos decir que si sus amores no eran «reales», sí lo eran sus amistades ${ }^{1}$.

Un episodio que aclara su profunda imbricación con la corte filipina es su entronización burlesca. En 1668 Pérez participó, por deseo del rey, en una fiesta del Retiro llevado en un carro, y en otro carro triunfal aparece en la celebración del cumpleaños de la reina madre, Mariana de Austria, en el entremés de El triunfo de Juan Rana, dentro de la fiesta mitológica de Pedro Calderón de la Barca Fieras afemina amor. Juan Rana hace el papel de su propia estatua, situada en su carro triunfal para la posteridad.

Pese a su indudable fama, como con tantos otros actores de nuestro teatro clásico, carecemos de documentos iconográficos que lo representen de manera fiable. De hecho, hay un disenso crítico sobre su forma física y sobre si esta tenía repercusión en su manera de actuar, en su percepción por parte del gran público y de los autores. En el presente trabajo, trazo una recopilación y análisis de sus retratos de modo que se presentan las semblanzas más cercanas a su persona.

\footnotetext{
${ }^{1}$ En el entremés de La loa de Juan Rana, atribuido a Moreto, habría también una alusión similar en la que Rana se congratula por su jubilación, puesto que así «ya denguno hace bulra de mis menguas / y ya no me mermuran malas llenguas». Bergman, "Juan Rana se retrata" (Madrid: Castalia, 1970), 65-73.
} 
La primera atribución que ha contado con un cierto acuerdo crítico de su contrahecha figura aparece en un retrato que se conserva en la Real Academia Española (Figura 1).

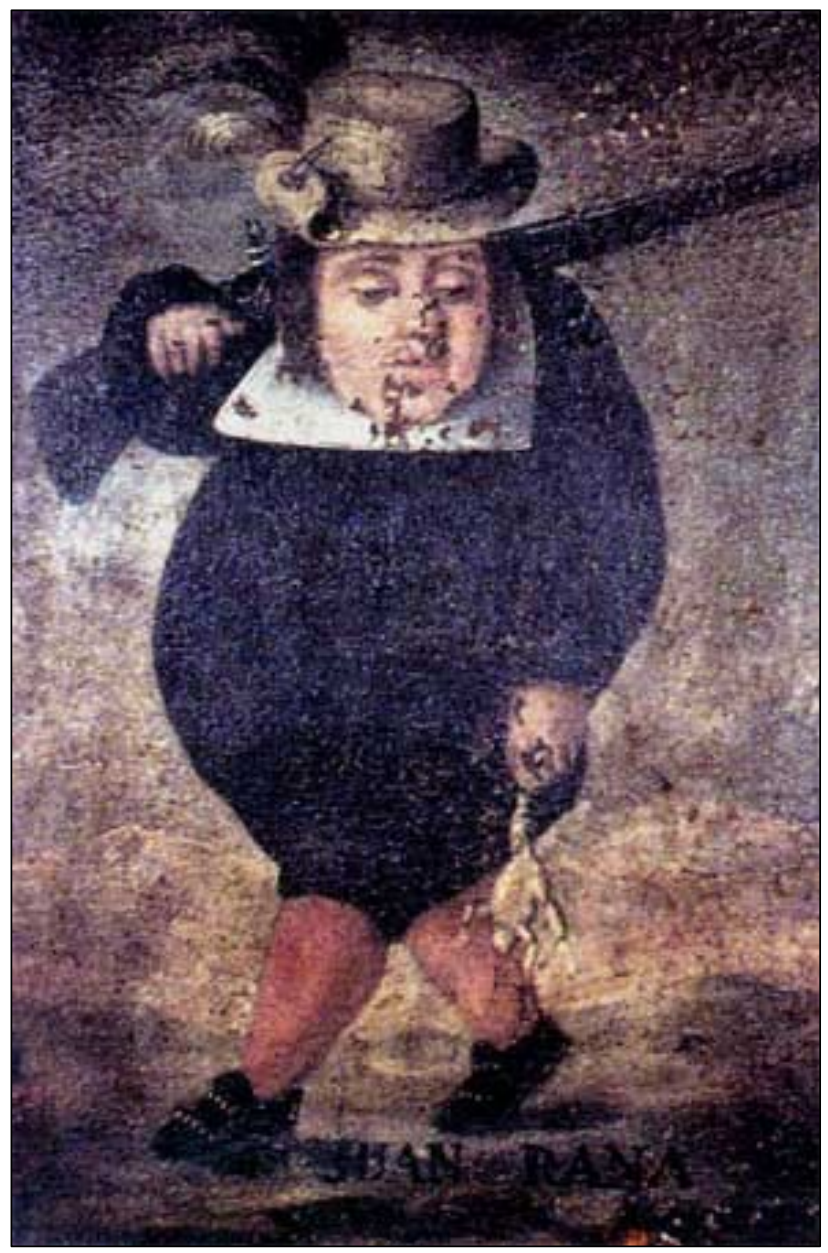

Fig. 1- Anónimo, Retrato de Juan Rana, óleo sobre lienzo. Final siglo XVII, RAE. 
El cuadro ha sido restaurado muy recientemente con motivo de la exposición que comisarió Francisco Sáez Raposo titulada Todo Madrid es teatro: Los escenarios de la Villa y Corte en el Siglo de Oro, en cuyo catálogo se puede encontrar una reproducción de la pieza ya restaurada $(2018,196-198)$. La restauración permite observar la vivacidad de los colores del natural, los detalles de las calzas y las plumas y un pequeño bigotillo que se le asoma a nuestro personaje.

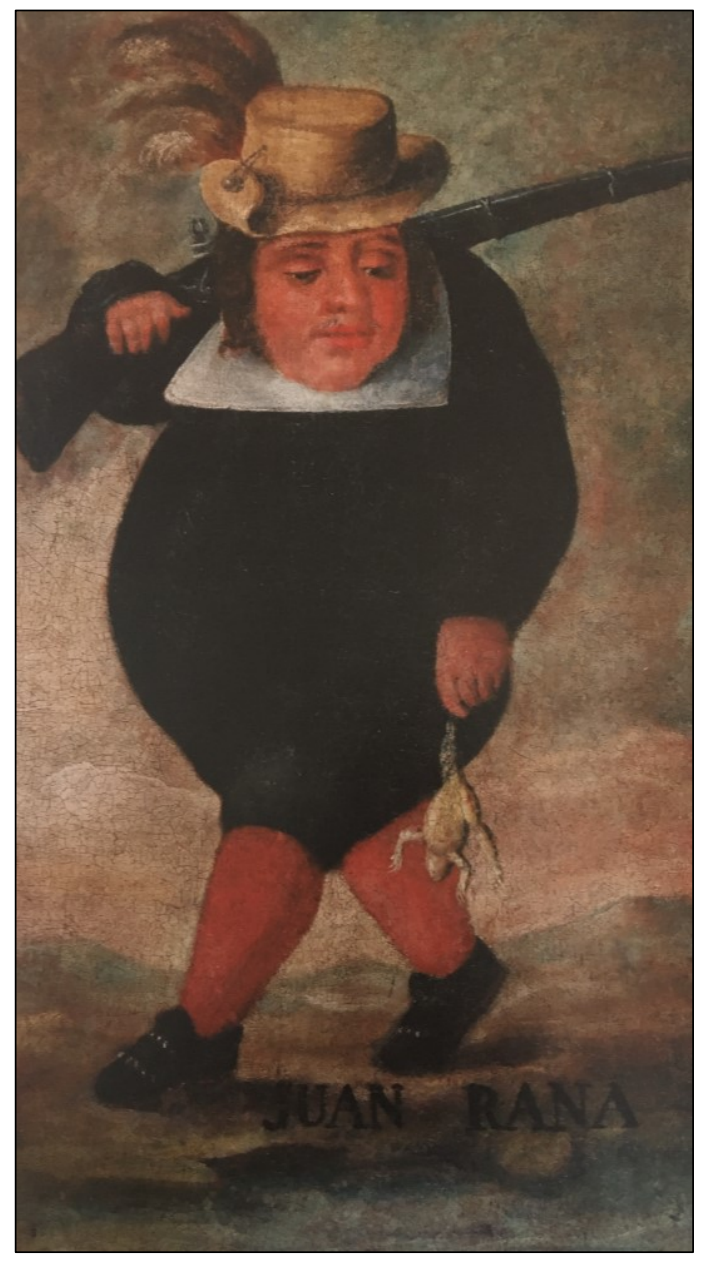

Fig. 1bis- Restaurado: Anónimo, Retrato de Juan Rana, óleo sobre lienzo. Final siglo XVII, RAE.

En ella Cosme Pérez, o su máscara Juan Rana (diferenciación fundamental, pues otros actores pudieron representarla), aparece vestido de negro, con una golilla de pala, sombrero de cazador y un arcabuz al hombro mientras sujeta con la mano izquierda una rana (supuesto trofeo de su jornada de caza). De ser cierta la atribución, Cosme Pérez sufriría de enanismo: calcula Alicia Álvarez Sellers (2007, 296), a partir del tamaño de ánima de los mosquetes o arcabuces (entre 80 centímetros y 1.60 
metros) que medía 1.20 metros de altura. Unas letras de molde forman el nombre y apellido JUAN RANA, puede que incluso trazadas con regla y cartabón aprovechando la línea que marca el pie izquierdo y de una antigüedad de unos 200 años, según la calígrafo Concepción Ferrero (Álvarez Sellers 2007, 306). Hanna Bergman sitúa el cuadro en la década de los 50 o 60 al suponer que fue el que originó los entremeses El retrato de Juan Rana, de Sebastián de Villaviciosa, el Retrato vivo, de Agustín de Moreto, y El retrato de Juan Rana (1651), de Antonio de Solís. Dice la investigadora: «precisamente por ser un hecho tan insólito y notorio, inspiró a los tres poetas la idea de justificar su existencia dentro de la modalidad de teatro entremesil a la que pertenecía exclusivamente la máscara cómica Juan Rana [...] En 1651 distingue la reina a Juan Rana concediéndole una pensión vitalicia. De la misma década, pues, juzgo la ejecución del cuadro y la composición de los entremeses que se refieren a él» (1970, 72-73). Alicia Álvarez Sellers data la obra en los alrededores de 1680. Se fundamenta en tres aspectos principales: la golilla en forma de pala que aparece en el retrato juanranesco es el modelo común en la década de los 80 del siglo XVII, las medias no son las habituales de color blanco, sino de color rojo, que las hace tardías en el siglo, y los zapatos, que en lugar de ser planos llevan hebilla, por lo que podría tratarse de los «zapatos de golilla» (2007, 302-304). Esta investigadora ha planteado serias dudas al respecto de que el retrato de la RAE sea, en realidad, de Juan Rana, sino de su máscara (2007). Se trata este de un enano que aparece con vista fija en el suelo, con el pelo largo y, posiblemente, una golilla cuadrada. Como resume Francisco Sáez Raposo «Se considera realizado en el siglo XVIII, ya muerto el actor, es decir, que no reflejaría sus rasgos físicos reales sino la imagen estereotipada que habría dejado en la mente de los españoles de la época» $(2018,198)$.

Esta es, con mucho, la imagen atribuida a nuestro personaje más conocida en nuestros momentos. De hecho, es posiblemente la imagen única con la que se relaciona Juan Rana por parte del público general. Esto queda claramente demostrado en la reciente producción (2019) de la magnífica compañía Ron Lalá, Andanzas y entremeses de Juan Rana (Ron Lalá/Compañía Nacional de Teatro Clásico), que incluye los entremeses Los dos Juan Ranas, El toreador y El triunfo de Juan Rana de Pedro Calderón de la Barca; Los galeotes de Jerónimo de Cáncer; El retrato vivo de Agustín Moreto; el anónimo El infierno, y fragmentos de los entremeses El doctor Juan Rana, El ventero, Los muertos vivos y $A l$ cabo de los bailes mil de Luis Quiñones de Benavente; La noche de san Juan y La boda de Juan Rana de Jerónimo de Cáncer; Juan Rana poeta de Antonio de Solís; Los locos, anónimo, y Mojiganga de las visiones de la muerte, de Calderón de la Barca. En ella el actor y músico Miguel Magdalena aparecen ataviado siguiendo esta representación.

Además, se incluyen numerosas referencias y juegos escénicos basados en lo contrahecho de su figura. La relación entre la obra y el retrato pictórico es tal que en el cartel promocional de la misma aparece Magdalena en la misma pose del cuadro de la Real Academia con un laúd en su mano derecha y con el cuadro citado en la izquierda. 


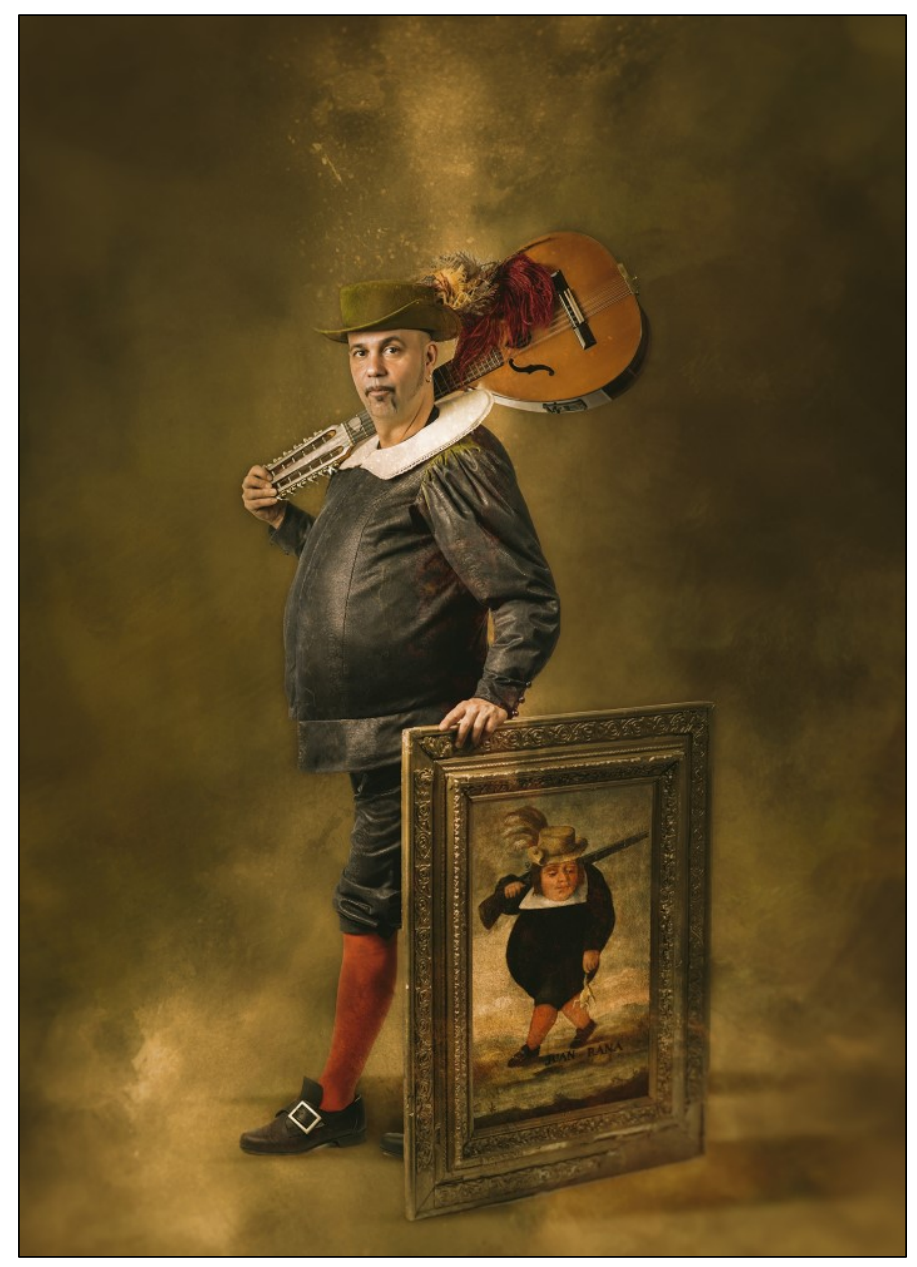

Fig. 2- David Ruiz, Cartel Promocional de Andanzas y entremeses de Juan Rana, Ron Lalá/CNTC, reproducida con permiso del autor.

Más allá de las fotografías de posado, la documentación gráfica existente al respecto de la puesta en escena muestra que la gestualidad, mímica y kinesia actorales están profundamente influidas por esta representación. En la siguiente fotografía de actuación, correspondiente a la puesta en escena del entremés El triunfo de Juan Rana de Pedro Calderón el actor imita abiertamente esta pose ${ }^{2}$.

2 El curioso lector encontrará la ficha completa en la siguiente URL: https://ronlala.com/portfolio/juanrana/ 


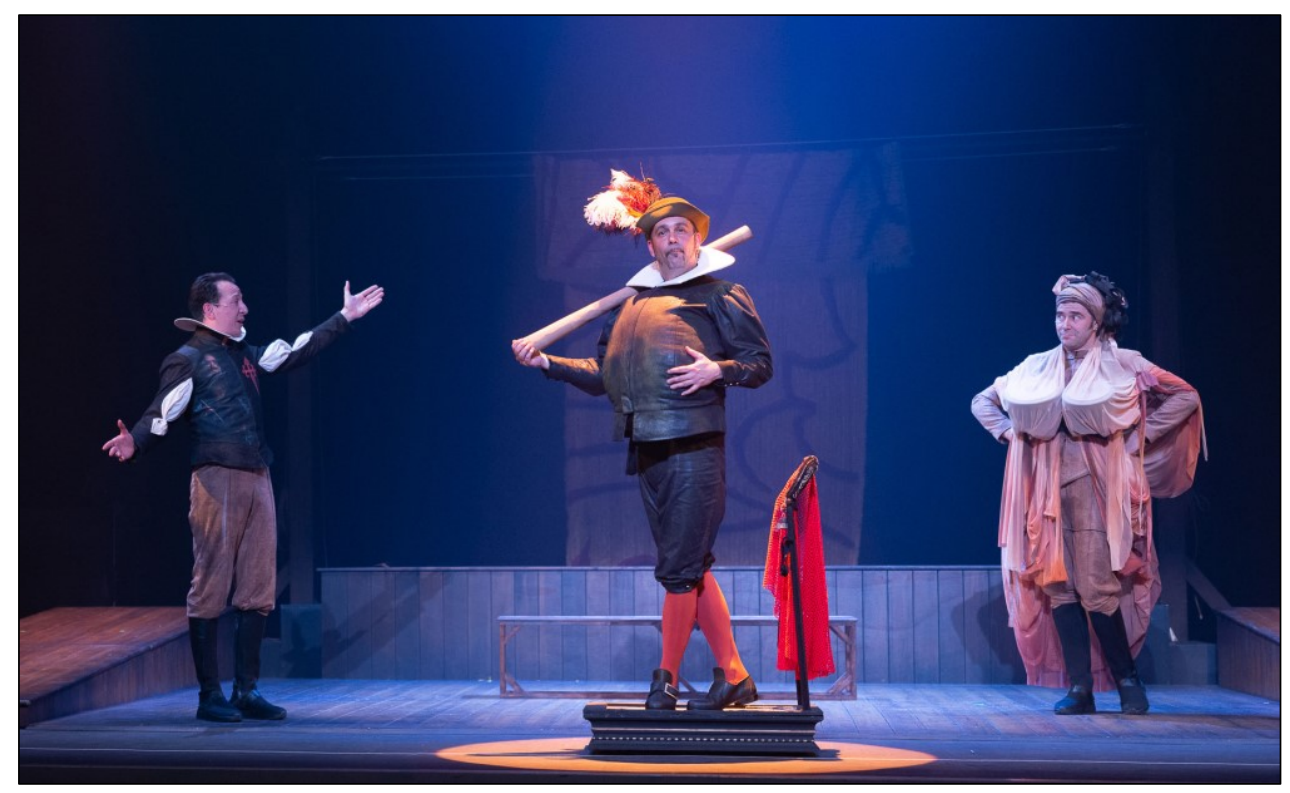

Fig. 3- David Ruiz, Momento de Andanzas y entremeses de Juan Rana, Ron Lalá/CNTC, fotografía de David Ruiz, reproducida con permiso del autor.

Una reproducción de este mismo cuadro tiene una importante función dentro de la puesta en escena. Así, en la representación del entremés anónimo El infierno un roll-up desplegable con esta icónica imagen sustituye al actor.

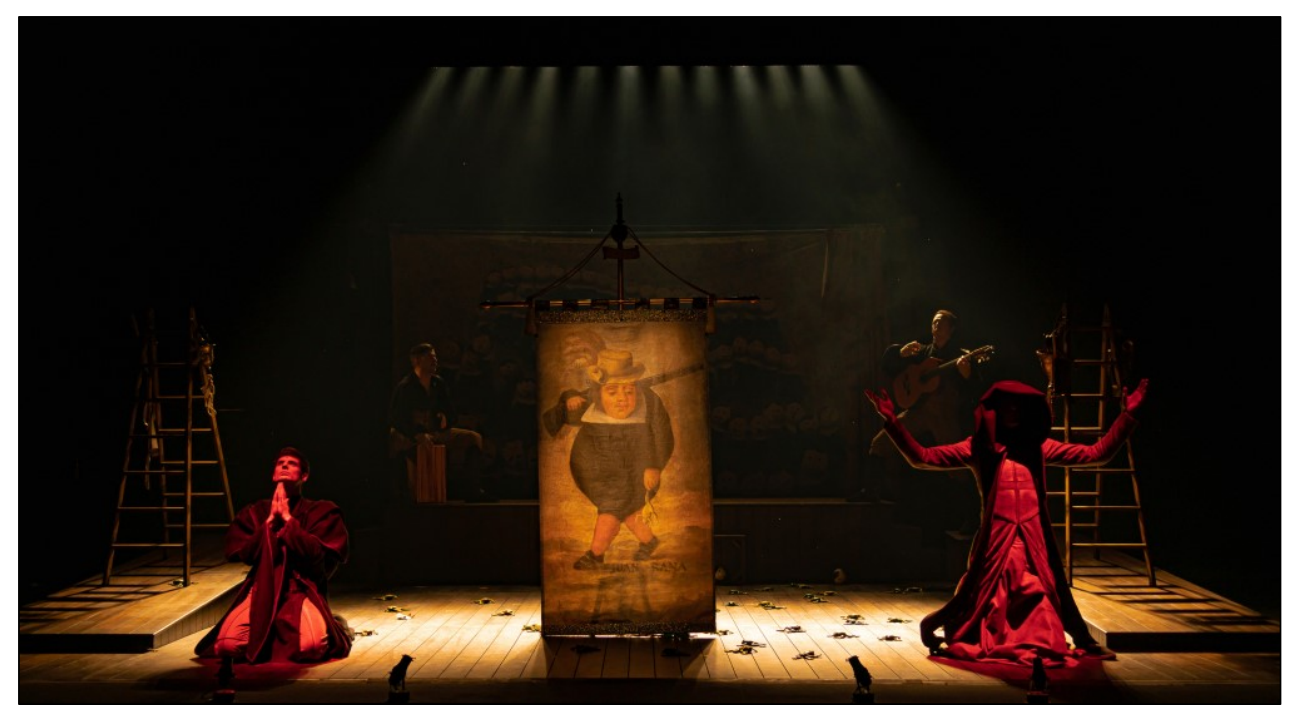

Fig. 4- David Ruiz, Momento de Andanzas y entremeses de Juan Rana, Ron Lalá/CNTC, fotografía de David Ruiz, reproducida con permiso del autor. 
Un segundo documento pictórico puede servir para medir los contornos iconológicos del personaje-actor. Como ya he adelantado en un trabajo anterior (Vélez-Sainz, 2015, 93-204), me parece indudable que la tabla sita en la Real Academia guarda un parecido indiscutible con el cuadro de Gaspar de Crayer Retrato de Felipe IV con lacayo o Felipe IV junto a dos servidores $(215 \times 163 \mathrm{~cm}$; Madrid. Ministerio de Asuntos Exteriores. Palacio de Viana, Pérez Preciado cat. 122; Figura 5) ${ }^{3}$.

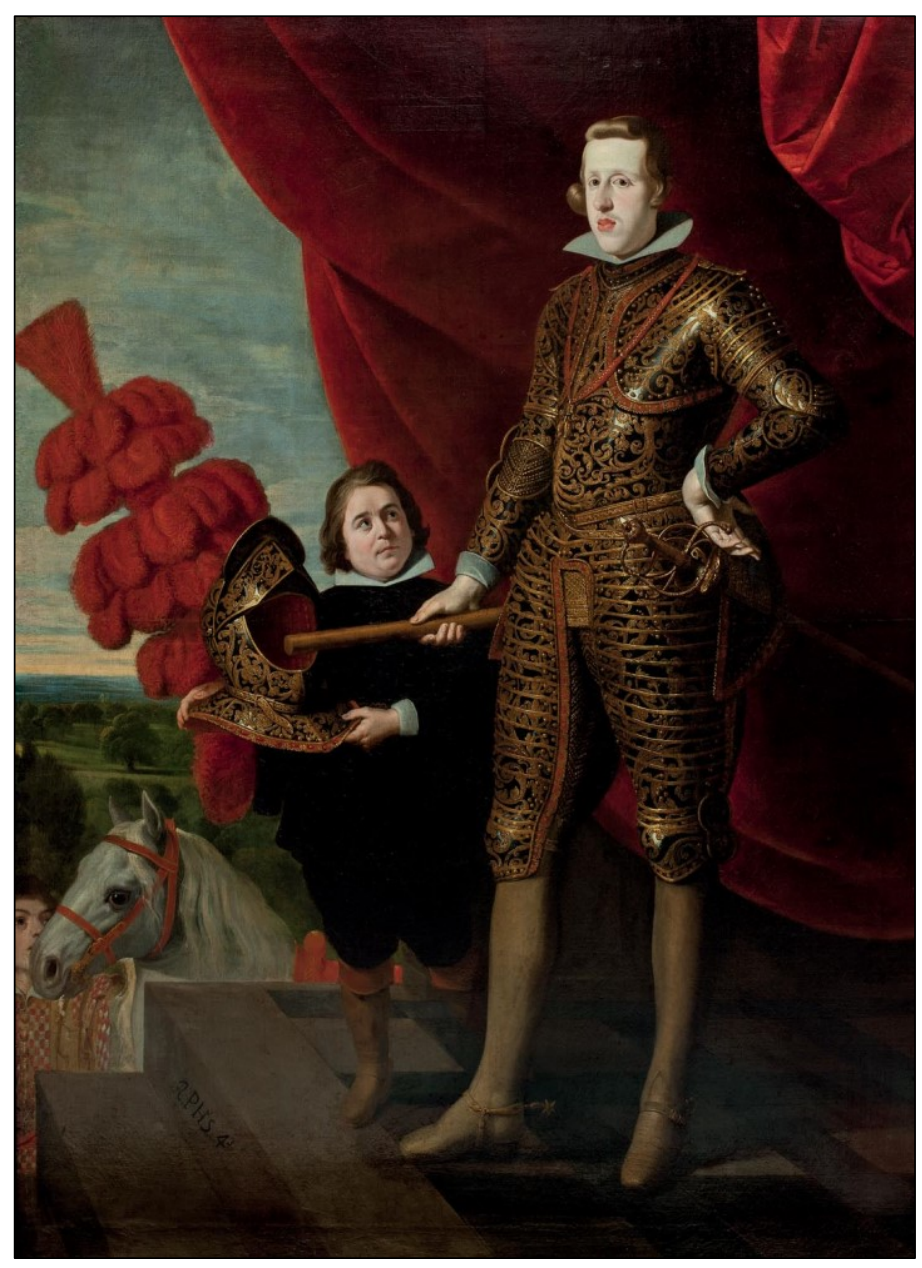

Fig. 5- Gaspar de Crayer, Felipe IV junto a dos servidores, óleo sobre lienzo (215 x $163 \mathrm{~cm})$. Ca. 1627-1632, Ministerio de Asuntos Exteriores y de Cooperación.

Gaspar o Caspar de Crayer (Amberes, 1582-Gante, 1669) fue un pintor barroco flamenco en la estela de Rubens y favorito entre las colecciones del momento.

${ }^{3}$ Amplia es la bibliografía del cuadro, vid. entre otros, López Navío (1962, 275), López Rey (1963, 361 y 1966), Díaz Padrón (1965, 238 y 1976, 1093), Vlieghe (1972, 257). Para un desarrollo de la historia patrimonial del cuadro a partir de su presencia en catálogos vid. Pérez Preciado (2008). 
En este cuadro encontramos a Felipe IV con una lujosa armadura de parada de azul negro con ribetes dorados en posición mayestática, con un cetro en la mano derecha mientras la izquierda descansa gentilmente sobre su cadera. En el centro del cuadro un enano vestido de negro con golilla y botas sujeta el yelmo con un penacho de plumas mientras mira hacia el rostro del monarca.

Los dos personajes están de pie en un estrado al que se llega por una serie de escalones; en el final se lee la inscripción: «R PHS 4z». Detrás de ellos unas cortinas rojas dobladas tapan la mayor parte del fondo (¿quizá un lacius curtius teatral?). Tras él se adivina un bosque, posiblemente un coto de caza, en el que un segundo lacayo sujeta un caballo blanco. Al igual que en los retratos de Velázquez, destaca el estigma de los Austrias, un gran prognatismo, frente olímpica y labios belfos, con un rostro severo y triste, en medio de una sinfonía de grises. Este pasa por ser uno de los retratos de Crayer más rubensianos, especialmente en la solución adoptada para el monarca. Un cuadro del propio Rubens presenta a Felipe IV solo con un cortinaje rojo detrás en posición erguida. Según Vlieghe, el modelo para el retrato del rey será Rubens, especialmente a través del retrato de Felipe IV que se conservaba en la Kunsthaus de Zurich hasta 1985, cuando un loco quemó el cuadro ${ }^{4}$, aunque también tiene ciertas analogías con los retratos de Van Dyck ejecutados en Amberes entre 1627 y 1632, lo que ha servido para fechar la composición del cuadro de Crayer ${ }^{5}$.

El cuadro de Crayer perteneció al marquesado de Leganés, en concreto al I Marqués de Leganés, don Diego Mexía de Guzmán y Dávila (h. 1580-1655), especialista áulico en lo referido a los Países Bajos e importante mecenas de las artes. Rubens se refería a él en 1628 como «tra gli maggiori ammiratori di quest’arte che siano al mondo» (Pérez Preciado 2008, I 5). En su tesis doctoral sobre Leganés, José Juan Pérez Preciado describe la inmensa colección del marqués, que alcanzó un total de mil trescientas treinta y tres obras, reunidas en los años en que éste conoció el auge de su carrera política y militar. Este es el primer cuadro de Crayer que parece haber poseído Leganés. En el inventario post morten realizado en 1655, documento de tasación de las pinturas firmado por Andrés Potestad en mayo de 1655, utilizado por López Navío y por Pérez Preciado, se lee: «Un Retrato del Rey Phelipe quarto nro señor harmado de todas harmas doradas un enano con el murrion y un lacayo de su libres con un cauallo Blanco de mano de gaspar de Kraer $\mathrm{n}^{\circ}$ çiento y veinte y dos y le taso en mill y çient Reales» ${ }^{6}$

El cuadro se documenta con seguridad en poder de Leganés en 1637, aunque es más que probable que fuera adquirido en 1634, cuando realizó su último viaje a Flandes. Como indica Pérez Preciado: «no hay datos que confirmen la presencia del cuadro en Madrid antes de 1637, es más que probable que para 1634 Leganés ya tuviera la pintura en su poder, cuando importó de los Países Bajos un amplio número de

\footnotetext{
4 Recoge la noticia Der Spiegel (23 de septiembre de 2004): http://www.spiegel.de/kultur/gesellschaft/attacken-gegen-kunst-faeuste-messer-saegen-saeure-a319538.html. (consultado el 24 febrero de 2015).

${ }^{5}$ Vlieghe 1972, p. 257

${ }^{6}$ Cit. en Pérez Preciado II, El marqués de Leganés y las artes (Tesis Doctoral sin publicar, Universidad Complutense de Madrid, 2008), 105, cat. 122.
} 
retratos» (Pérez Preciado 2008, I 707). Permaneció en el palacio de San Bernardo, durante la vida del marqués de Leganés, pasando por herencia a la casa de Altamira. En 1726 se considera una copia de Jordaens y se da nombre al enano: «Un Rettrato de Phelipe $4^{\circ}$ con Belasquillo que estta vestido de negro y un Penacho en las manos, y un caballo blanco de tres baras de alto; y dos de ancho copia de jordan, $\mathrm{n}^{\circ}$ 122321» (Pérez Preciado 2008, II 106). La confusión con «Belasquillo» se puede deber a que el anónimo informante mezcle a Lezcano (o «Lezcanillo»), el «Niño de Vallecas», objeto de una famosa pintura de Velázquez también en posesión de Leganés; más que probablemente el lapsus se deba a la interrelación entre objeto del cuadro (Lezcanillo) y sujeto del mismo (Velázquez). Permaneció en poder de la familia hasta principios del siglo XIX, cuando llamativamente y pese a seguir conservando el mismo nombre para el enano, se creía que era una pintura realizada por Jan van Kessel: «otro por Juan Banquesel, qe tiene ademas a Velazquillo y su jaca» (Pérez Preciado 2008 II, 107). A principios del XIX fue robado, junto con un conjunto de otras obras y, tras ser devuelto a sus propietarios en 1815, fue ofrecido en venta en 1827 en Londres, cuando de nuevo se considera obra de Crayer, y se sigue considerando el mismo nombre para el enano. Tras pasar por varias colecciones privadas londinenses fue adquirido por el Estado en 1958 y destinado al Ministerio de Asuntos Exteriores.

El enano que sujeta el yelmo guarda un más que notable parecido con el cazador-enano «Juan Rana» de la tabla de la RAE. Ambos llevan un traje negro de fiesta con golilla (cada uno de su momento), tienen el pelo castaño, las mismas facciones regordetas, un atuendo diferenciado en los pies (botas en el de Crayer, calzas rojas en el de la RAE) y la misma baja altura. Si el de la RAE es indudablemente un «enano» (Álvarez Sellers 2007, 297), el del retrato de Crayer ha sido nombrado como tal en todos los catálogos. Los dos personajes parecen, claramente, representar el mismo enano vestido de negro con golilla.

Este podría tratarse de uno de los cuadros que mejor representara al actor (si fuera en efecto el objeto de la pintura). Algunos datos parecen incidir en la identificación. En primer lugar, el enanismo era uno de los rasgos característicos del personaje Juan Rana, no necesariamente del acto Cosme Pérez. Era típico de los dramaturgos hacer aparecer a Juan Rana en escena con otros personajes u objetos de gran tamaño para recalcar su tamaño (Sáez Raposo 2005, 161). En segundo lugar, tampoco es óbice para descartar la atribución el que no se mencione al conocido actor en el cuadro. El marqués de Leganés, ávido coleccionista, poseía varios cuadros dedicados a enanos, bufones y hombres de placer. Entre otros que estaban activos en los años treinta en la corte de Felipe IV encontramos los retratados por Velázquez como Juan de Austria, Pernia, Cárdenas, Calabacillas y Pablo de Valladolid (Pérez Preciado 2008 II, cat. 545, 546, 547, 549, 553) ${ }^{7}$. Algunos de ellos permanecen

${ }^{7}$ Estos incluyen los siguientes ítems del catálogo de la colección del marqués de Leganés: 542. Retrato del bufón Pejerón; 543. El enano Mordateo; 544. Retrato del bufón Martín de Guas; 545. Retrato del bufón don Juan de Austria; 546. Retrato del bufón Barbarroja — «dado que el ejemplar del Bufón Calabacillas (Cat. 549), atribuido al propio Velázquez, no repite el modelo del cuadro conocido del Prado, no es posible afirmar con rotundidad que este de don Juan de Austria sea réplica del Juan de Austria del Prado» (Pérez Preciado 2008 I, 385)—; 547. Retrato del bufón Juan de Cárdenas; 549. El bufón calabacillas; 550. Retrato del 
innominados ya desde los catálogos antiguos. Por ejemplo, del catálogo de Pérez Preciado encontramos bufones sin nombre en Retrato de Enano (Cat. 541, Madrid, Museo del Prado), de Juan van der Hamen, el anónimo Retrato infantil (Cat. 548) y un cuadro, hoy perdido, de un bufón con plumas (Cat. 1305: «Mas un retrato de un bufón de medio talle con un plumaje blanco en la cabeza y esta tocando una guitarra $n^{\circ}$ trezientos y çinco la taso en duçientos Reales 2200» (Pérez Preciado 2008 I, 819)). Estos retratos estaban destinados por el marqués a sus casas en la villa de Leganés, conocida como la Huerta. En tercer lugar, no se puede argumentar que Crayer nunca estuvo en España pues, muy posiblemente, Crayer trabajara con otro retrato (hoy perdido) para los contornos y el lacayo. De hecho, contamos con otro cuadro que imita a este.

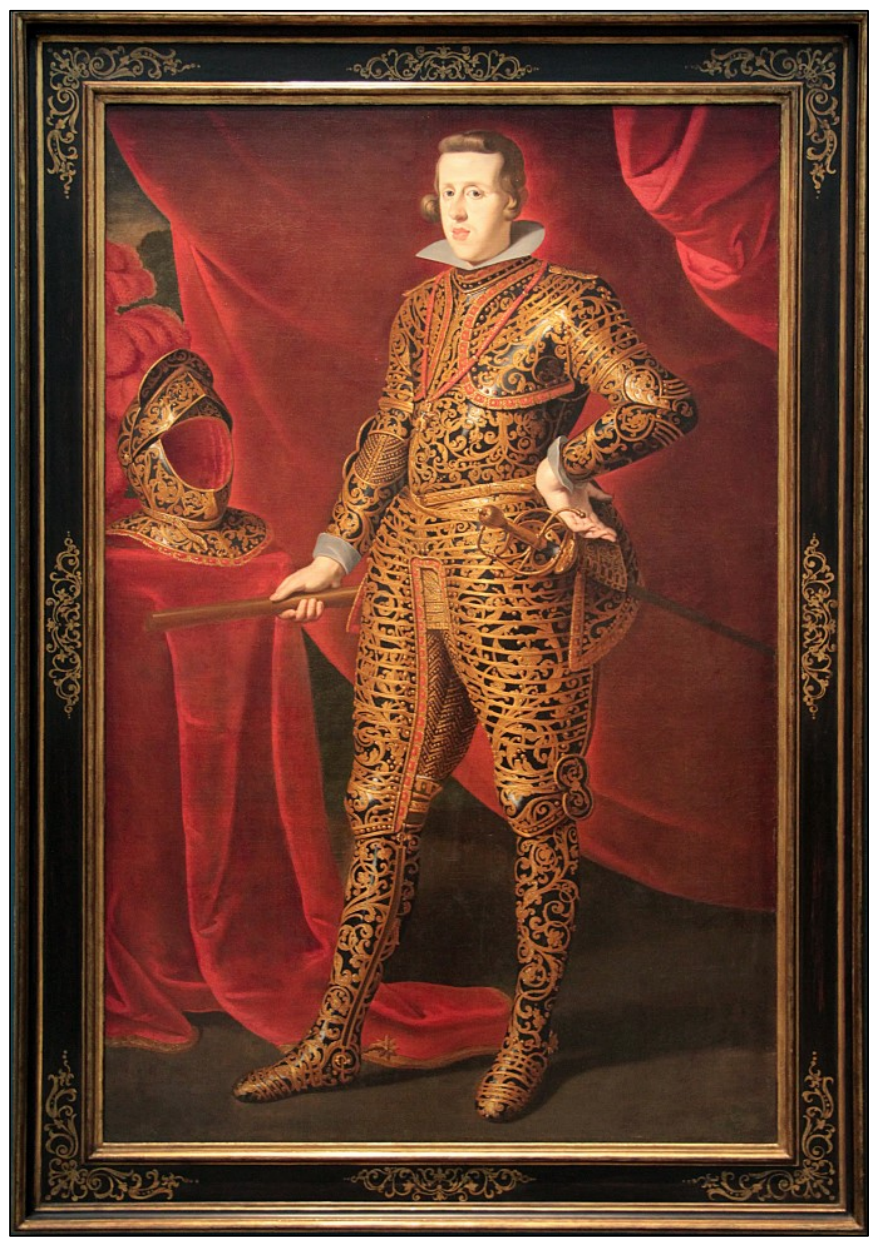

Fig. 6- Gaspar de Crayer, Felipe IV en armadura de gala. Ca. 1628. Metropolitan Museum de Nueva York.

bufón Escobedo; 551. Retrato del bufón Cisneros; 553. Retrato del Bufón Pablo de V alladolid — «Un retrato entero de pablillos de velazquez del $n^{\circ}$ quinientos y çinquenta y tres le taso en duzientos Reales $2200 »-$. 
En el Metropolitan Museum de Nueva York se conserva una réplica de la figura del rey, sin la presencia del enano ni la del caballo, también autógrafa de Crayer, que fue dada a conocer por López Rey como obra de Juan Bautista Maino a partir de aseverar una cierta semejanza entre este cuadro y el retrato de Felipe IV incorporado en el segundo plano de su Recuperación de Babia (Madrid, Museo del Prado). En esta ocasión el cortinaje rojo ha sustituido al resto de los personajes. Las deudas entre uno y otro cuadro son, sin duda, obvias y no sería descabellado que se tratara de una copia posterior (López Rey 1963, 361; López Rey 1966).

Felipe IV con "Juan Rana", nombre que he propuesto para el cuadro en mi trabajo anterior, indicaría una posible función de este como hombre de placer del monarca. En el catálogo de José Moreno Villa, Juan Rana aparece directamente como «bufón» de la corte $(1930,134)$, pues, en definitiva, su apelativo batracio no está muy lejos de aquellos bufones cuyo nombres y calificativos derivan de lo animalesco: liendre, pulga, mosca, mico, gato, mona y, claro, rana (Bouza 1991, 134), aspecto que comparten con los personajes de entremés e, incluso, con muchos graciosos. Se trata, pues, de ese restringido círculo de actores que pululaban alrededor de la corte del Rey Planeta mendigando favores a la par que hacían reír al monarca. Como indicaba en mi anterior trabajo:

De resultar cierta la atribución, un nuevo documento iconográfico de Gaspar de Crayer nos situaría al actor Cosme Pérez/Juan Rana en una órbita muy cercana a la real, favorecido, por la compañía de Tomás Fernández. El marqués de Leganés, coleccionista y mecenas de las artes, contaba con esta obra en España ya desde 1634, lo que situaría a nuestro actor, junto con un conjunto de gente de la farándula, cerca del favor real en unos contornos próximos a los de los hombres de placer. De hecho, incluso si el cuadro de la RAE no resultara fiable como método de identificación de la máscara, sin duda, podríamos indicar la interconexión entre ese personaje (fuera quien fuera) y el lacayo que soporta el yelmo con las plumas de Felipe IV en el retrato de Gaspar de Crayer. Nos encontramos en estos terrenos que van de lo teatral a lo áulico y a lo bufonesco, de este complejo mundo de la risa del Barroco del que participaban al alimón los reyes y sus lacayos. (2015, 202-203)

Como podemos observar, en mi artículo nunca indico que la tabla de la RAE sea otra cosa que una atribución a un actor áureo. Por alguna razón, sin duda atribuible a mi redacción, no parece entenderlo así Tania de Miguel (2017, 325-356).

Hay otro rastro iconográfico muy interesante abierto hace casi 50 años por Phyllis Dearborn Massar (1977, 365-375+445- 455). Dearborn Massar contempla de la posibilidad de que haya una segunda representación gráfica de Juan Rana en el manuscrito de La fábula de Perseo y Andrómeda de Calderón que se conserva en la Houghton Library de la Universidad de Harvard (Ms Typ 258). Últimamente Sáez Raposo (2011, 42-43) y Tania de Miguel (2017, 325-356) siguen esta interesante línea. Como mantiene Dearborn Massar:

Beneath this obviously comic figure Baccio has written Juan Rana. Juan Rana was a real person whose actual name was Cosme Perez, and he was the gracioso, the court 
fool. Since the part of Bato was comic, it is probable that Rana played him, inasmuch Baccio notes in his 1656 letter that "Giovan Rana" played a part in the play of that year at Buen Retiro, contributing his own buffooneries. $(1977,372)$

En efecto, como aclara Sáez Raposo, «[1] o obra fue representada el 18 de mayo de 1653 en el Coliseo del Buen Retiro por iniciativa de la infanta María Teresa de Austria para celebrar el restablecimiento de la reina Mariana de Austria tras una enfermedad» (2011: 42-3). Es decir, se trata, de nuevo, de una obra de ámbito cortesano.

En esta comedia Cosme hizo el papel del gracioso Bato y la escenografía corrió a cargo de Baccio del Bianco. Contamos con un magnífico manuscrito, depositado en la Houghton Library de Harvard University, que consta de 150 folios $(31 \times 21,5 \mathrm{~cm})$. Como indica Rafael maestre en su edición crítica: «104 corresponden a la fábula escénica, 46 en la partitura musical y dos figuras en blanco cierra comillas. [...] tanto los diseños como el texto están realizados en papel verjurado de color marfil casi igual» (Maestre 1994, 26-28). El manuscrito cuenta con 11 dibujos «para acompañar, de modo ornamental, el manuscrito de la comedia, ya que iba a ser un regalo de Felipe IV a su suegro, Fernando III, emperador del Sacro Imperio Romano Germánico» (Sáez Raposo 2011, 42, nota 17).

Hasta ahora la figura de Juan Rana ha sido identificada en tres de los grabados. Sáez Raposo encuentra a Juan Rana sólo en el grabado de la escena inicial del acto tercero, Triunfo de Perseo sobre Medusa (véase fig. 7). En este grabado, una mano incluyó en el ángulo inferior izquierdo del escenario, aunque completamente fuera de este, a Cosme Pérez (con la leyenda «Juan Rana» debajo de él), que aparece mirando al público encuadrado en una especie de territorio intermedio entre la ficción escénica y la realidad fuera de ella $(2005 b, 44)$.

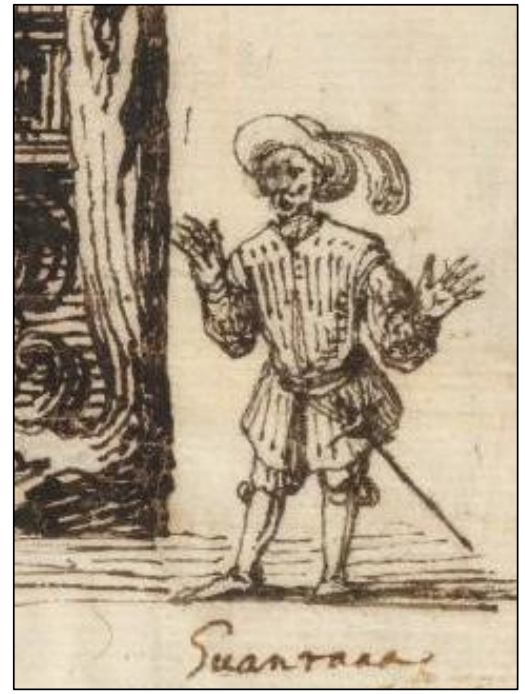

Fig. 7- Fol. 12. Ms. Typ 258. Houghton Library, Harvard University. 
Después del trabajo de Sáez Raposo, María Luisa Lobato revisó de nuevo las ilustraciones y, basándose en el parecido y el vestuario, llegó a la conclusión de que el actor también es uno de los personajes de la derecha en la escena del Infierno (2001, 208):

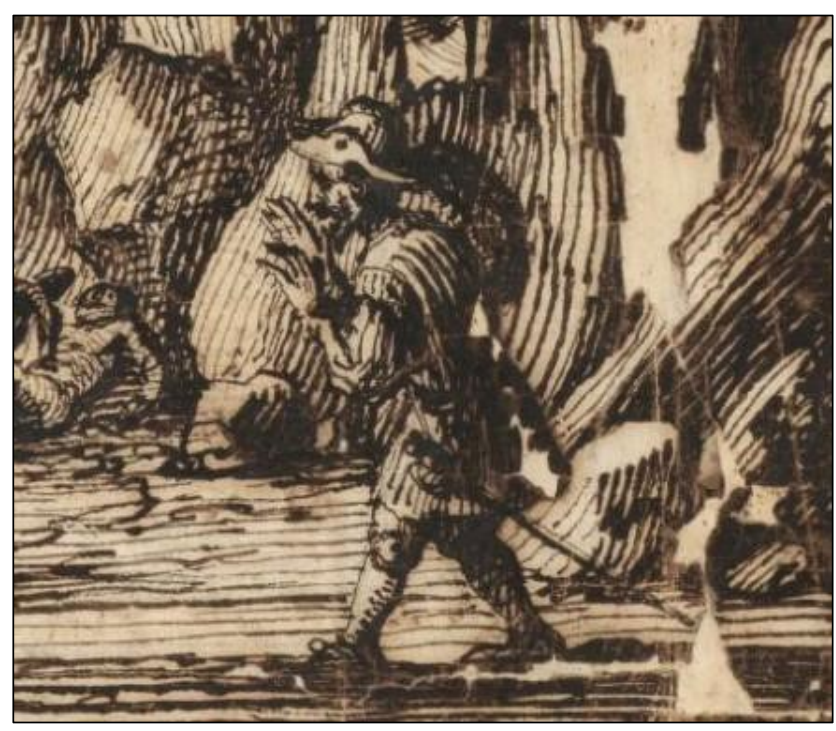

Fig. 8- Fol. 57. Ms. Typ 258. Houghton Library, Harvard University.

Por su lado, de Miguel mantiene que la imagen a la izquierda de la escena de la apoteosis del folio 98 v. $(2017,349)$ puede indicar una tercera representación del propio Juan Rana en la obra:

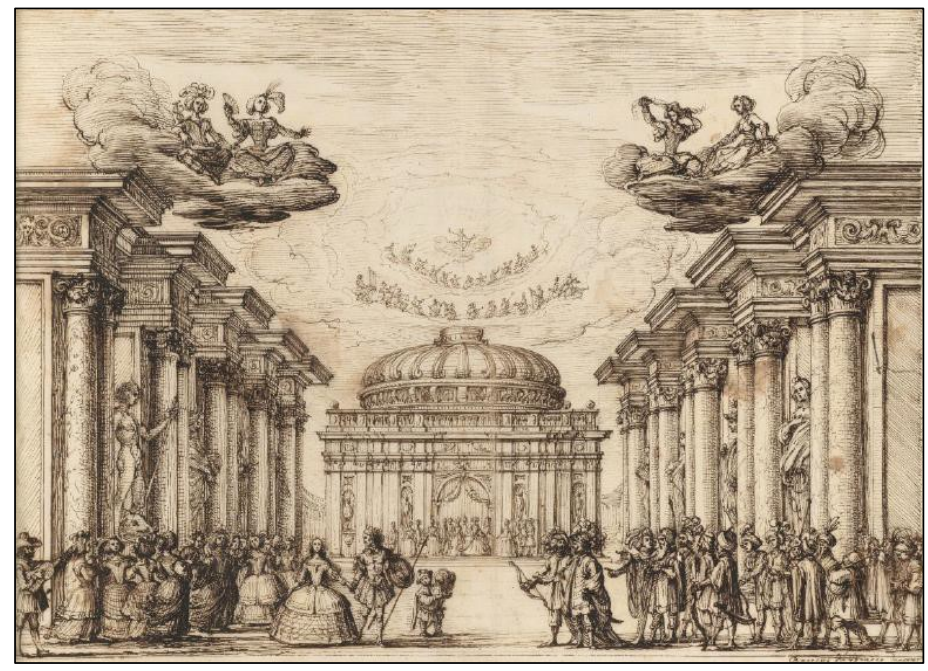

Fig. 9- Fol. 98v. Ms. Typ 258. Houghton Library, Harvard University. 
Reproducimos a continuación el detalle:

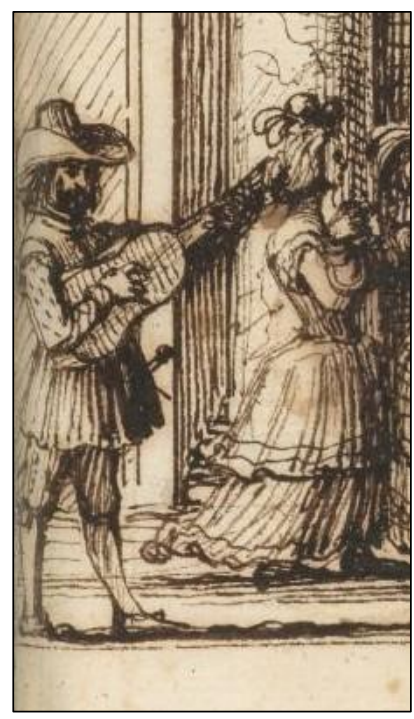

Fig. 9bis- Detalle de fol. 98v. Ms. Typ 258. Houghton Library, Harvard University.

Pudiera ser, aunque echo en falta la pluma del sombrero y se ha de notar que se cambia el bigote por una barba.

De ser esta atribución indiscutible, como la tratan los críticos mencionados, sería, sin duda, de un altísimo interés. Por ejemplo, la postura de las manos de las figuras 7 y 8 podría sugerir que Juan Rana era identificado como un ser palmípedo pues se entrevén unas suaves membranas entre las distintas falanges de los dedos del actor. La figura 9 incidiría en sus dotes musicales. Es decir, nos ofrecerían un contorno más completo del actor más allá de la máscara.

En mi opinión, no podemos tener tampoco (muy lamentablemente) certeza de la atribución de este personaje a Juan Rana. El famoso ms. Typ 258 de la Houghton Library de Harvard que alberga el volumen de La fábula de Perseo y Andrómeda tiene anotaciones marginales de dos letras minúsculas distintas y una mayúscula que podemos adscribir a cualquiera de estas manos (o a una tercera). El ejemplo más claro ocurre, precisamente, con esta atribución. El único actor o máscara que se destaca de toda la producción es este Juan Rana del fol. 76 (Ms. Typ 258. Houghton Library, Harvard University). Se trata de un tintado que ha quedado en color cobrizo en el que se lee "Juanrana". La palabra se inicia con una "J" i larga/jota mayúscula con un trazo volado hacia la izquierda parecida a una "G", y se rompe el trazo para pasar a la segunda letra. El resto de la palabra se escribe en un solo trazo. Veamos: 


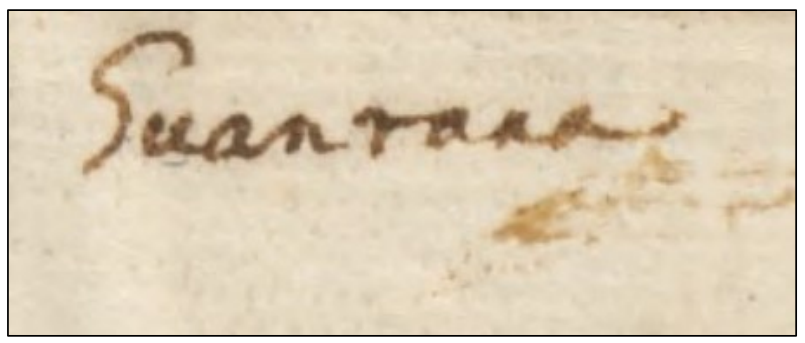

Fig. 10- Fol. 76. Ms. Typ 258. Houghton Library, Harvard University. Transcripción: Juanrana.

Esta letra tiene lugar tan solo en este folio 76. Compárense ahora las notas marginales del resto de los folios 8, 29, 39, 57, 88 y 99:

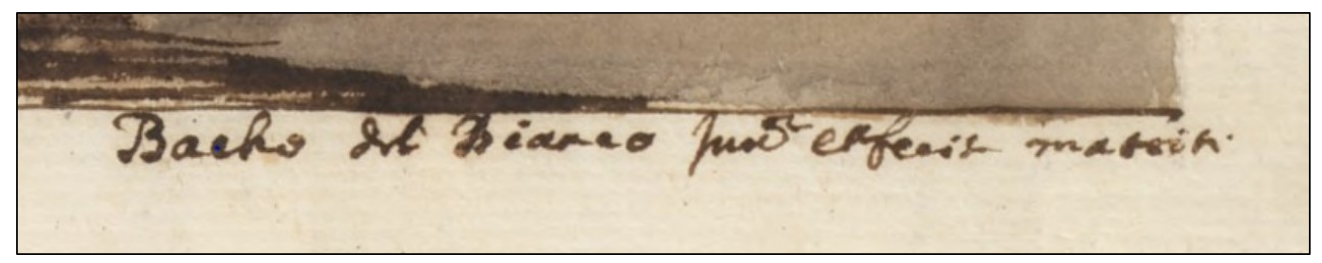

Fig. 11- Fol. 8. Ms. Typ 258. Houghton Library, Harvard University.

Transcripción: Bacho del Bianco Inv[enit] et Fecit ¿Machina?
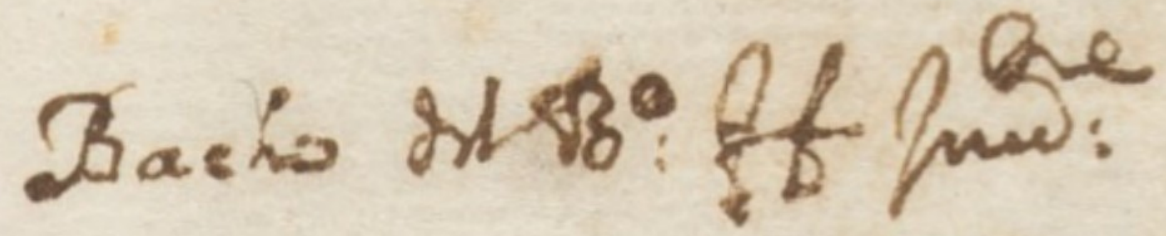

Fig. 12- Fol. 29. Ms. Typ 258. Houghton Library, Harvard University.

Transcripción: Bacho del B[ianc]o [florentino en rúbrica] Inv[entor].

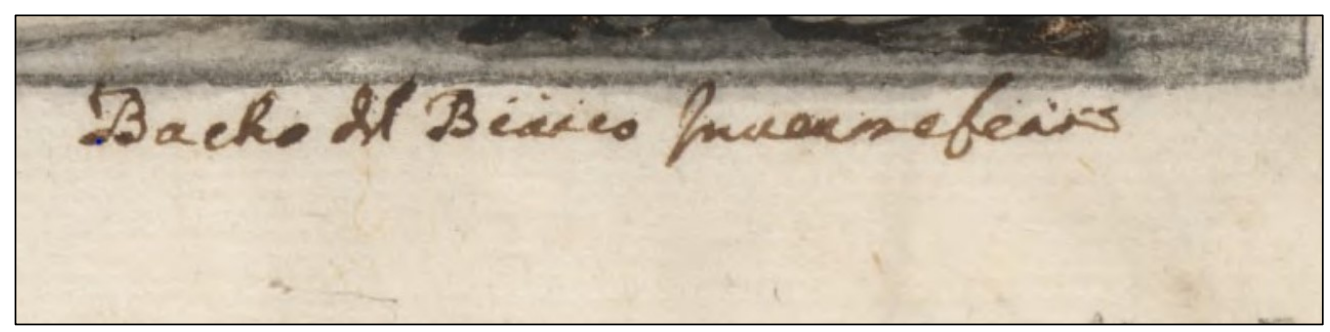

Fig. 13- Fol. 39. Ms. Typ 258. Houghton Library, Harvard University. Transcripción: Bacho del Bianco invenit fro. 


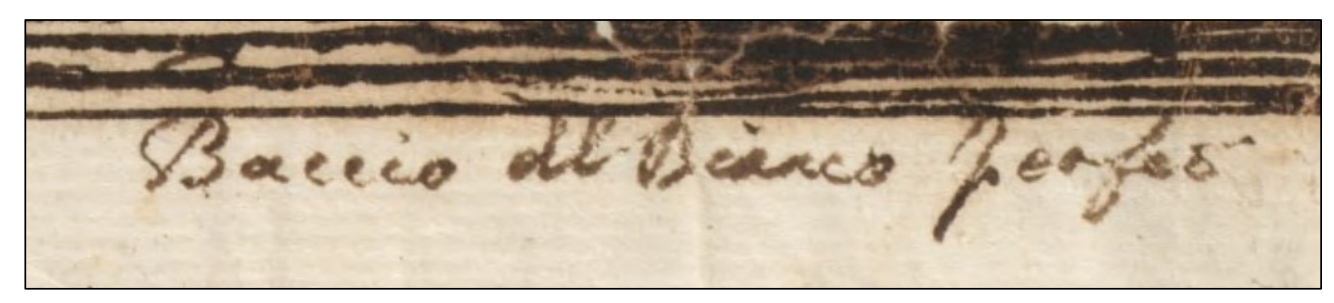

Fig. 14- Fol. 57. Ms. Typ 258. Houghton Library, Harvard University. Transcripción: Baccio del Bianco Inv[entor] [florentino en rúbrica].

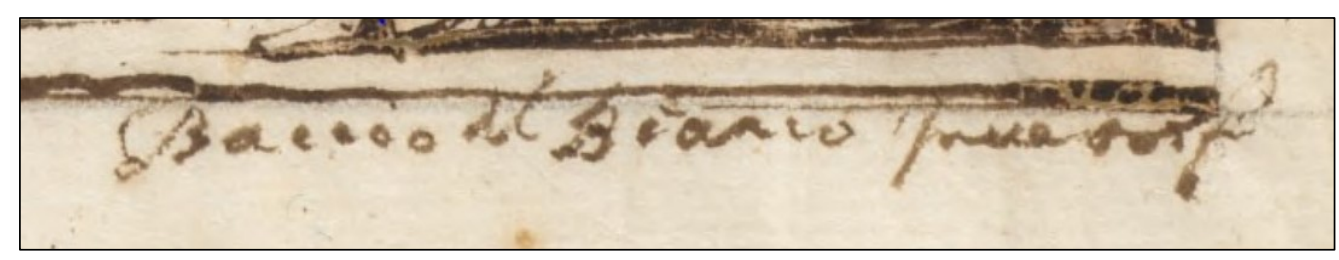

Fig. 15- Fol. 88. Ms. Typ 258. Houghton Library, Harvard University. Transcripción: Baccio del Bianco Inventor [florentino en rúbrica].

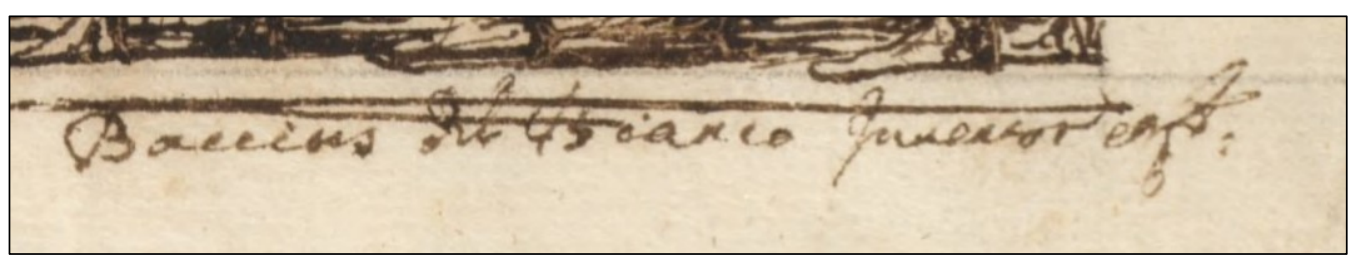

Fig. 16- Fol. 99. Ms. Typ 258. Houghton Library, Harvard University. Transcripción: Baccio del Bianco Inventor [florentino en rúbrica].

Se trata, sin duda, de una segunda letra que ocurre tan solo una vez. Como vemos, en el resto de las reproducciones de los folios la i larga/jota mayúscula se escribe de manera opuesta con un único movimiento rápido en zig-zag y trazo único. Es decir, este modelo de i larga/jota mayúscula se produce exclusivamente en este grabado. Asimismo, el color de la tinta es mucho más oscuro. Lo más lógico es que cronológicamente se sitúe la letra del escribano de los folios 8, 29, 39, 57, 88 y 99 y después la del folio 76. El primero ofrece los datos fundamentales de puesta en escena, el autor de la escenografía y, ya en su versión en mayúscula, incluso el lugar de representación (Madrid) en el fol. 12. 


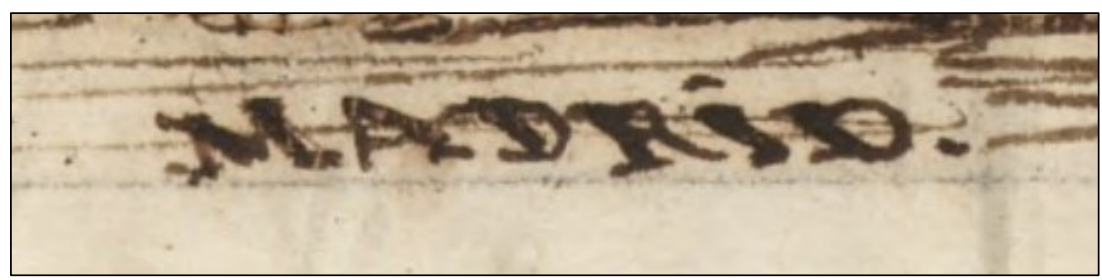

Fig. 17- Fol. 12. Ms. Typ 258. Houghton Library, Harvard University. Transcripción: MADRID.

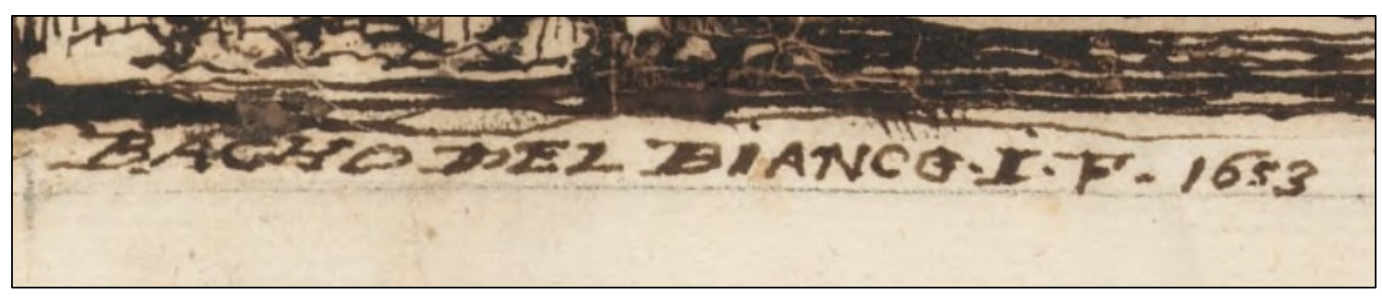

Fig. 18- Fol. 12. Ms. Typ 258. Houghton Library, Harvard University. Transcripción: BACHO DEL BIANCO I-V-1653.

¿Cómo resolver el problema de las dos caligrafías? En este punto, creo que no tenemos respuestas claras. Pudiera ocurrir que la primera de las letras correspondiera a alguien del taller al que Felipe IV encargó la suelta de este modo, la letra del segundo escribano sería la del propio del Bianco lo que parecería recalcar la posible confusión con una "G". No obstante, tanto Dearborn Massar como Maestre atribuyen la primera letra al propio del Bianco. Citamos de la primera crítico: «In the inscription at the lower right, INVENTOR BACHO DEL Bianco $\mathrm{F}^{\circ}$, Baccio probably intended the word inventor to credit his invention of the stage machines, as well as his drawing; $\mathrm{F}^{\circ}$ stands for Fiorentino» $(1977,369)$. De este modo, el autor de la nota marginal del folio 76 sería posterior por lo que más que probablemente se trate de un informante no contemporáneo y, por lo tanto, poco fiable. Algo parecido ha ocurrido para descartar la viabilidad de la atribución de la anotación de "Juan Rana" en el famoso "retrato" de la RAE. Lamentablemente también hay razones, pues, para descartar también este segundo rastro.

Me encantaría acabar este trabajo con una luz de esperanza al respecto de descubrir la semblanza real de nuestro actor, pero me es imposible. Antiguamente una semblanza era una "semejanza". De hecho, la palabra proviene del verbo "semejar": "(del Latín vulgar "similiare") Tener una cosa el aspecto de otra que se expresa de modo que puede creerse que es esa" (Moliner 1131), esto es lo que le permite a fray Luis de León decir en De los nombres de Cristo que «la perfección de todas las cosas... consiste en que cada una de ellas tenga en sí a todas las otras y, en que, siendo una, sea todas cuanto le fuere posible. [...] La cual semejanza es, si conviene decirlo así, el pío [ansia] general de todas las cosas» $(1583,396)$. No me queda, de momento, más remedio que conformarme con haber bosquejado las semejanzas existentes entre la idea contemporánea y colonizada del personaje/máscara Juan Rana, el actor Cosme 
Pérez, y el conjunto iconográfico que los acompaña. Tiempo vendrá en el que estudiosos más hábiles que este que escribe logren descifrarlo. 


\section{REFERENCIAS BIBLIOGRÁFICAS:}

Álvarez Sellers, Alicia. 2007. Del texto a la iconografía: aproximación al documento teatral del siglo XVII. Valencia: Universidad de Valencia.

Bass, Laura. 2008. The Drama of the Portrait: Theater and Visual Culture in Early Modern Spain. University Park: The Pennsylvania State University Press.

Bergman, Hannah. "Juan Rana se retrata", en Homenaje a Rodríguez Moñino. Estudios de erudición que le ofrecen sus amigos o discipulos hispanistas norteamericanos. Madrid: Castalia, 1970.

Bouza, Fernando. 1991. Locos, enanos y hombres de placer en la corte de los Austrias. Madrid: Ediciones Temas de Hoy.

Ceán Bermúdez, Juan Agustín. 1800. Diccionario histórico de los más ilustres profesores de las Bellas Artes en España, vols. 1-6. Madrid: Viuda de Ibarra.

Cotarelo y Mori, Emilio. 1908. Colección rarísima de entremeses, bailes y loas. Madrid: Imp. de la Rev. de Archivos.

Davis, Charles \& John Varey. 2003. Actividad teatral en la región de Madrid según los protocolos de Juan García de Albertos, 1634-1660, vols. 1-2. London: Támesis Books.

Dearborn Massar, Phyllis. 1977. "Scenes for a Calderón Play by Baccio del Bianco", en Master Drawings 15, no. 4: 365-375 + 445-455.

Díaz Padrón, Matías. 1965. "Gaspar de Crayer, un pintor de retratos de los Austria", en Archivo español de Arte, 151: 229-244.

Díaz Padrón, Matías. 1976. Museo del Prado. Catálogo de Pinturas I, Escuela Flamenca. Madrid: Museo del Prado.

Norman Shergold \& John Varey. 1985. Genealogía, origen y noticia de los comediantes de España. London: Tamesis.

Granja, Agustín de la. 2001. "Los dos testamentos de Cosme Pérez, alias Juan Rana", en Actas del V Congreso de la Asociación Internacional Siglo de Oro (Münster 1999). Christoph Strosetzki. Madrid/Frankurt am Main: Iberoamericana/Vervuert, 652-662.

Herradón, Óscar. 2017. “Juan Rana. El actor que revolucionó el Siglo de Oro”, en Historia de Iberia Vieja, 144, (junio 2017). 
Lobato, María Luisa. 1999. "Un actor en Palacio: Felipe IV escribe sobre Juan Rana", en Cuadernos de Historia Moderna: 79-111.

López Navío, José Luis. 1962. "La gran colección de pinturas del Marqués de Leganés”, en Analecta Calasanctiana, 8: 259-330.

López Rey, José. 1966. "Sobre la atribución de un retrato de Felipe IV a Gaspar de Crayer", en Archivo Español de Arte, 154-155: 195-196.

López Rey, José. 1963. "A portrait of Philip IV by Juan Bautista Maino”, en The Art Bulletin, 14: 361-363.

Madroñal Durán, Abraham. 2012. Seis estudios en busca de un actor: Juan Rana y el entremés del siglo XVII. Madrid: Ediciones del Orto.

Miguel, Tania de. 2017. "El aspecto físico de Cosme Pérez", en Anagnórisis. Revista de investigación teatral, 16: 325-356.

Moreno Villa, José. 1930. Locos, enanos, negros y niños palaciegos: gente de placer que tuvieron los Austrias en la Corte española de 1563 a 1700. México: Editorial Presencia.

Pérez Preciado, José Juan. El marqués de Leganés y las artes. Tesis Doctoral sin publicar, Universidad Complutense de Madrid, 2008.

Ron Lalá, Compañía Nacional de Teatro Clásico. 2020. “Andanzas y entremeses de Juan Rana", https://ronlala.com/portfolio/juanrana/ (consultado el 27 de septiembre de 2020).

Sáez Raposo, Francisco. 2003. “Cosme Pérez, actor tudelano”, en Teatro, 19: 57-77.

Sáez Raposo, Francisco. 2004. "El origen del nombre artístico Juan Rana”, en Vozy letra, 15, no. 2: 33-58.

Sáez Raposo, Francisco. 2005. Juan Rana y el teatro cómico breve del siglo XVII. Madrid: Fundación Universitaria Española.

Sáez Raposo, Francisco. 2005. "Juan Rana en escena”, en La construcción de un personaje: El gracioso. Editado por Luciano García Lorenzo: Fundamentos, 317-50.

Sáez Raposo, Francisco. 2018. Todo Madrid es teatro: los escenarios en la villa y corte en el Siglo de Oro. Madrid: Comunidad de Madrid.

Serralta, Fedric. 1990. "Juan Rana: homosexual”, en Criticón, 50, 81-92. 
Thompson, Peter E. 2006. The Triumphant Juan Rana: A Gay Actor of the Spanish Golden Age. Toronto: University of Toronto Press.

Vélez Sainz, Julio. 2015. "Felipe IV con Juan Rana de Gaspar de Crayer: un posible nuevo documento pictórico para un actor calderoniano", en Calderón frente a los géneros dramáticos. Editado por Antonio Sánchez Jiménez: Ediciones del Orto, 193-204.

Vlieghe, Hans. 1972. Gaspard de Crayer, sa vie et ses æuvres, vols. 1-2. Bruxelles: Arcade.

Recibido: 9 de octubre de 2020 Aprobado: 13 de octubre de 2020 